\title{
ОСВОБОЖДЕНИЕ ТРУДА С ТОЧКИ ЗРЕНИЯ ТЕОРИИ АЛЬТЕРНАТИВНЫХ ФИНАНСОВ
}

\author{
(c) 2021 Лебедев Константин Николаевич \\ доктор экономических наук, профессор, профессор Департамента экономической теории \\ Финансовый университет при Правительстве Российской Федерации, Россия, Москва \\ E-mail: KNLebedev@fa.ru \\ ORCID: https://orcid.org/0000-0002-4846-8097
}

В настоящей статье развивается концепция стадий вытеснения трансфертного труда товарообменным трудом при капитализме. Она формируется на основе реконструкции стадий исторического процесса, состоявшего, наоборот, в вытеснении товарообменного труда трансфертным трудом по мере развития капитализма, выделяемых по признаку лишения индивидуальных производителей (ремесленников, кустарей) функций по управлению своими видами деятельности и передачи их капиталистам, а также на основе концепции обратного развития.

Ключевые слова: трансфертный труд, товарообменный труд, закабаление труда, инволюция, освобождение труда.

В соответствии с теорией альтернативных финансов, в современном мире наблюдается тенденция вытеснения трансфертных систем ресурсообеспечения их товарообменными альтернативами как более эффективными (более экономичными, доступными, менее токсичными). Такая тенденция должна наблюдаться и в сфере обеспечения экономики ресурсом «труд», т.е. трансфертный труд должен вытесняться товарообменным трудом как более эффективным по сравнению с первым (их характеристики даны в статье К.Н.Лебедева «Труд трансфертный и товарообменный», опубликованной в настоящем номере журнала «Экономические науки»). Данная статья посвящена вопросам теории процесса вытеснения трансфертного труда товарообменным при капитализме, а именно стадиям этого процесса.

Как и в общем случае, подобно, например, тому, как современному вытеснению трансфертной пенсионной системы (системы обеспечения в старости) товарообменной пенсионной системой предшествовал процесс вытеснения последней первой, современному вытеснению трансфертного вольнонаемного труда товарообменным должен был предшествовать исторический процесс вытеснения товарообменного вольнонаемного труда трансфертным. В нашей вышеуказанной статье было показано, что вольнонаемный трансфертный труд обоснованно трактуется как добровольное рабство, в связи с чем ранее имевший место процесс вытеснения вольнонаемного товарообменного труда трансфертным с полным основанием может быть назван закабалением труда, а современный обратный процесс - освобождением труда.

В качестве подхода к выделению стадий освобождения труда используем концепцию инволюции. Ранее мы уже использовали концепцию инволюции (обратного развития) в своих исследованиях - для подтверждения неизбежности исчезновения, или исторического характера, традиционных финансов - они возникли позже товарообменных систем ресурсообеспечения, являющихся имманентными человеческому обществу, и шли им на замену, следовательно, неизбежно отомрут, а также для выяснения последовательности исчезновения форм (натуральной, денежной) традиционных отраслевых финансов - натуральные традиционные финансы появились раньше денежных, например натуральные налоги появились раньше денежных, следовательно, первыми отомрут денежные традиционные финансы [2, с. 32-45]. С помощью концепции инволюции на основе реконструкции стадий исторического процесса закабаления (вольнонаемного) труда при капитализме могут быть выделены стадии его освобождения при том же капитализме, идущие в обратном порядке.

Предварительно отметим, что именно товарообменный труд является имманентным чело- 
веческому обществу, в том числе общественный. Как известно, человеческое общество возникло в результате осуществления людьми или семьями общих работ (охоты, рыбной ловли и т.д.), участники которых образовывали общины (первобытнообщинный строй). Следовательно, имманентным человеческому обществу был совместный труд рядовых участников работ и труд по управлению общими работами (общественнодолжностная деятельность), без которого они не могли осуществляться. При этом каждый участник общественного труда сам заботился об эффективности своего труда, не находился ни под чьим непосредственным управлением, т.е. его труд был самоуправляемым. Очевидно, что труд начальника охоты, начальника рыбной ловли и т.д., дополнительно исполнявшийся отдельными участниками общих работ, выступал самоуправляемым трудом, хотя бы потому, что соответствующие лица исполняли роль верховных начальников, т.е. начальников, не находившихся под чьим-то непосредственным управлением. Но совместный производительный труд участников общих работ в первобытных общинах также был самоуправляемым, поскольку начальники работ осуществляли лишь общее управление работами (например, подавали сигнал к началу работ). Труд всех участников общественного труда оплачивался по самой высокой цене, так как весь его продукт поступал в их распоряжение и распределялся на справедливой основе, предусматривавшей, в частности, надбавку начальникам работ за общее руководство. О соответствующих чертах общественного труда (самоуправляемость, полная оплата результата) в первобытных общинах говорят многочисленные наблюдения путешественников, ученых и пр. за экономическим бытом первобытных народов, открывшимся европейцам в связи с наступлением эпохи географических открытий. Известный российский ученый-историк экономического быта Н.И. Зибер в своем знаменитом произведении «Очерки первобытной экономической культуры» (1899) приводит, в частности, наблюдения натуралиста А.Уоллэса за общинным трудом на общественных полях туземцев о. Целебес, который отмечает, что над ними нет никакого надсмотрщика по урокам (отдельным операциям.- примеч. авт.), они работают как хотят, но под общим управлением своего старейшины. При этом они работают на самих себя, так как весь продукт принадлежит им. Как отмечает
Н.И.Зибер, завершая описание порядка дележа добычи у тегуэльчей, «кацик вообще получает большую долю» [5, с. 24]. Таким образом, изначально (до появления рабства) в человеческом обществе весь общественный труд был товарообменным, причем он был как индивидуальным (труд по общему управлению работами), так и производственно-кооперативным (совместный производительный труд при осуществлении общих работ). Отсюда, исходя из концепции обратного развития, человеческое общество в итоге должно вернуться к товарообменному труду.

В экономической науке концепция стадий исторического процесса закабаления труда при капитализме подверглась разработке, прежде всего, в марксисткой теории. Традиционно закабаление труда при капитализме рассматривается в ней на примере закабаления труда индивидуальных производителей, как правило, в промышленном секторе экономики. Промышленное производство перед началом этого процесса представляется как деятельность индивидуальных производителей (кустарей, ремесленников), сидящих по своим мастерским или домам, работающих на свои средства, самостоятельно осуществляющих свои снабжение и сбыт и определяющих способ производства своих товаров, состоящего из целого ряда операций. Так, В.И.Ленин, будучи руководителем «Союза борьбы за освобождение рабочего класса», созданного осенью 1895 г. путем объединения марксистских кружков Петербурга, в написанном им в тюрьме «Объяснении программы» (июнь - июль 1896 г.) социал-демократической партии [12], имея в виду промышленность, отмечал, что при старых условиях (т.е. до развития капитализма в России.- примеч. авт.) почти все богатство производились мелкими хозяевами [7, с. 87]. Марксистский автор А.И.Тюменев в своей «Истории труда» (1923) пишет, что тогда в производстве отдельных изделий, в частности, отсутствовало разделение труда, например ювелиры сами плавили металл, сплющивали его, чеканили, наводили эмаль, ремесленники сами изготавливали и необходимые им инструменты [9, с. 91].

С точки зрения теории альтернативных финансов, закабаление труда по мере развития капитализма представляет собой осуществлявшийся в значительной мере насильно (что характерно для развития традиционных финансов) процесс лишения работников, в дан- 
ном случае индивидуальных производителей (а не членов производственных кооперативов, или артелей), функций по управлению видом промышленной деятельности и передачи их работодателю, сопровождающийся соразмерным сокращением оплаты труда работников. Соответственно, освобождение труда (на основе концепции инволюции) представляется как происходящий в обратном порядке возврат соответствующих управленческих функций работникам с необходимым повышением оплаты труда за их осуществление. В марксистской же теории, также развивающей концепцию освобождения труда, о чем говорят, прежде всего, названия марксистских партийных групп (см. выше), например «Освобождение труда», как называлась марксистская группа, созданная в 1883 г. Г.В.Плехановым в Женеве [6], освобождение труда трактуется не как возврат непосредственным производителям отобранных у них функций по управлению их видами деятельности, а как приведение положения (оплаты труда, условий труда, социальных гарантий) рабочих после того, как они оказались по максимуму лишенными этих функций, в соответствие с этим состоянием их труда, так как положение рабочих оказалось значительно хуже подобающего ему. Приведение положения рабочих в соответствие с содержанием их труда, как известно, должно было произойти насильственным путем, а именно путем захвата рабочими, направляемыми социал-демократической партией, государственной власти и последующего отъема предприятий у капиталистов с передачей их в собственность государства (государственнокапиталистический путь создания общества будущего) или самих рабочих (производственнокооперативный путь) [1].

Очевидно, в рекламных целях соответствующее повышение оплаты труда (заметим, всего лишь до трансфертного уровня) трактовалось как присвоение рабочими всего излишка над их содержанием, который теперь будет идти на удовлетворение потребностей не капиталистов, а самих рабочих, на полное развитие их способностей и равноправное пользование всеми достижениями науки и искусства [7, с. 97]. Заметим, что марксистское освобождение труда фактически является его окончательным закабалением, поскольку теперь этот перешедший под почти полное управление работодателей труд становится покорным, например не прекращается из-за забастовок, саботажа и т.д. Соответственно, закабаление труда рабочих (или рабочего класса) в марксизме представляется как поэтапное ухудшение положения работников в связи с развитием капитализма. При этом в качестве причины ухудшения положения рабочих рассматривается рост предложения труда по сравнению со спросом на него со стороны капитала, т.е. причина конъюнктурного, а не долгосрочного характера. Соответственно, и качественные сдвиги в производстве, образующие стадии закабаления труда, в марксистской науке выделяются по признаку соответствующего влияния на рынок труда. Поэтому стадии закабаления труда в теории альтернативных финансов и марксистской теории отчасти не совпадают. Далее, рассмотрим стадии закабаления труда согласно теории альтернативных финансов, сравнивая их со стадиями закабаления труда в марксистской теории. Это следующие стадии:

1. Лишение непосредственных производителей функций управления сбытом и снабжением их видов деятельности и передача этих функций работодателям. Эта первая стадия закабаления труда капиталом, связанная с развитием капитализма, фактически совпадает с таковой, выделяемой марксистским автором А. И. Тюменевым, согласно которому данная стадия, начавшись с выдачи торговыми капиталистами кустарям ссуд деньгами или материалами, закупки всего выпуска кустарей за определенный срок наперед и т.д. [9, с. 80], завершилась разобщением производителя и рынка, произошедшим в форме такого качественного сдвига в производстве, как возникновение домашней промышленности, когда кустарь или ремесленник все сырье получает от раздаточной конторы бывшего торгового капиталиста и туда же сдает готовую продукцию по заранее определенным расценкам. При этом производитель получает за труд уже не цену товара, а низкую плату, которая, как подчеркивает А.И. Тюменев, едва дает ему возможность поддерживать свое существование [9, с. 87-88]. С точки зрения теории альтернативных финансов, образование домашней промышленности не может вызвать падения оплаты труда до прожиточного минимума, так как товарообменный труд отделяет от стадии трансфертного труда не одна, а целый ряд стадий закабаления труда. Попытка А.И. Тюменева объяснить соответствующее ухудшение положения производителей их желанием как можно бы- 
стрее продать свои изделия [9, с. 87], т.е. резким превышением предложением труда (в виде его продуктов) спроса на него, толкнувшим цену на труд существенно вниз по сравнению с ее долгосрочным уровнем, не выглядит убедительной, тем более, что он сам приводит данные, наоборот, о росте оплаты труда кустарей во Франции в предмануфактурный период (период расцвета французских мануфактур - XVI-XVIII вв.), когда заработная плата французского рабочего с 900 фр. в конце XV в. выросла до 1230 фр. в начале XVI в. [9, с. 92], что говорит о том, что образование домашней промышленности происходило в условиях отставания предложения труда кустарей от спроса на него, толкнувшего цену на труд вверх так, что ее динамика, напротив, не отразила долгосрочной тенденции к понижению оплаты труда. Интересно, что В.И. Ленин, по крайней мере применительно к России, не выделял такой стадии закабаления труда, как возникновение домашней промышленности, относя ее развитие к периоду роста в России фабричной промышленности [7, с. 88]. При этом, по В.И. Ленину, фактически развитие домашней промышленности, в подтверждение нашего вывода, способствовало росту оплаты труда кустарей - вождь пролетариата отмечал, что работой на дому тогда было занято множество лиц, и ее раздавали фабриканты и купцы, не успевавшие расширить свои фабрики [7, с. 88].

2. Лишение непосредственных производителей функции распределения собственного труда во времени (при управлении производством) и ее передача работодателям. Работники стали подчиняться трудовому распорядку, устанавливаемому для них капиталистами. Очевидно, что передача данной функции работодателям привела к очередному долгосрочному сокращению оплаты труда непосредственных исполнителей, прежде всего, потому, что ее исполнение требовало существенных усилий со стороны работодателей, а не потому, что ее исполнение требовало существенных усилий от бывших кустарей. Эта стадия закабаления труда соответствует такому отмечаемому в истории экономического быта качественному сдвигу в производстве, произошедшему в ходе развития капитализма, как появление и развитие мануфактур, т.е. объединение ранее разрозненных кустарей, как одной, так и разных специальностей, в одном помещении, но до того момента, когда в них было осуществлено разделение труда. Интересно, что
А.И. Тюменев не рассматривает данный период развития мануфактурного производства в качестве стадии закабаления труда, т.е. ухудшения положения рабочих. А.И. Тюменев не пишет, что это привело к сокращению оплаты труда рабочих, а отмечает лишь мотивы, побудившие капиталистов к соответствующему преобразованию производства. Это, в частности, стремление капиталистов получить экономию на распределении материалов между работниками и получении от них готовой продукции, которое теперь происходит внутри помещения, на инструментах, которые теперь переходят из рук в руки, а не являются отдельными комплектами, имеющимися у каждого работника [9, с. 90]. В отличие от А.И. Тюменева, В.И.Ленин, если судить о его взглядах по тому же «Объяснению программы», считал, что вытеснение кустарей и ремесленников, обусловившее опережающий рост предложения труда и соответствующее ухудшение положения трудящихся, началось сразу же после появления крупной промышленности. Как писал В.И.Ленин, на место мелких ремесленных заведений встали крупные фабрики и заводы, которые стали разорять кустарей и крестьян, превращая их в наемных работников, масса прибывающего из деревни голодного люда сбивала цены на труд [7, с. 88-89]. Из-за того, что наемный труд стал единственным источником существования, а оплата труда по вышеуказанной причине снижалась, положение работников стало ухудшаться - как отмечал В.И.Ленин, рабочие стали жить в лачугах, переполненных сырых и холодных квартирах, даже в землянках, устроенных рядом с новыми заводами, отдавать все свое время работе и загонять на нее жен и детей [7, с. 90]. Поскольку В.И.Ленин называет введение разделения труда (или совместного труда, который является значительно более производительным, чем труд по одиночке) второй переменой, которую дает замена мелкого производства крупным [7, с. 90], хотя и именует крупное производство фабрично-заводским (т.е. не выделяет в развитии крупной промышленности мануфактурного периода), все же можно предположить, что В.И.Ленин выделял в качестве отдельной стадии закабаления труда первоначальный процесс сосредоточения разрозненных кустарей в общих помещениях, еще не сопровождавшийся введением разделения труда.

Интересно, что В.И.Ленин отмечал крайнюю ценность для непосредственных произво- 
дителей возможности самостоятельно распределять свой труд во времени (моральный ущерб, который наносит им утрата данной возможности), трактовал подчинение работника трудовому распорядку фабрики как утрату им воли. Как он писал в «Объяснении программы», ранее каждый работник отдыхал, оставлял работу в праздник, если его празднуют в окрестности, а фабрика, нанимая работника, не обращает никакого внимания на обычный образ жизни работника, его привычки, семейное положение, умственные потребности, заставляет разрывать на части свой отдых, работать ночью и в праздник при работе сменами [7, с. 94].

3. Превращение работников из лиц, управляющих всем производством, в лиц, управляющих отдельными операциями, и передача управления производством в целом работодателям, сопровождающаяся очередным долгосрочным сокращением оплаты труда работников. Эта стадия закабаления труда, выделяемая теорией альтернативных финансов, фактически совпадает с таким выделяемым в истории экономического быта качественным сдвигом в производстве, как введение на мануфактурах разделения труда, когда работник вместо ряда последовательных операций по изготовлению готовой продукции начинает выполнять только одну операцию, что и превращает его в управляющего только отдельной операцией. Разделение труда приводит к экономии времени на переходе работника от одной операции к другой, на перемене инструмента и т.д., повышению производительности труда за счет увеличения ловкости, с которой выполняются операции, создания более приспособленных к отдельным операциям инструментов, экономии на ремесленной подготовке вследствие передачи простых операций на исполнение лицам, не имеющим таковой. Однако при этом работник превращается в автомат, его деятельность лишается всякого духовного содержания, он превращается в физического и нравственного калеку [9, с. 91-92]. Введение разделения труда рассматривается как стадия закабаления труда и в марксистской концепции его закабаления. Так, по В.И.Ленину, работодатели в этих условиях фактически получают возможность дополнительного снижения оплаты труда работников за счет того, что последние привыкают к исполнению только одной операции, в связи с чем им сложно найти другую работу [7, с. 90], что означает сокращение спроса на их труд со стороны капитала.

А.И.Тюменев приводит данные о снижении оплаты труда работников в период развития мануфактур во Франции, закончившийся введением на них разделения труда. Если в начале XVI в. зарплата французского рабочего составляла 1230 фр., то в период расцвета мануфактур в XVI-XVIII вв. она непрерывно падала, составив в начале XVII в. 750 фр., а в конце - 516 фр. [9, с. 92]. При этом, согласно марксистской концепции закабаления труда, это падение вызвано растущим превышением предложения труда рабочих над спросом на него, а согласно нашей концепции закабаления труда - долгосрочным снижением его ценности в результате отъема у непосредственных производителей функций управления своими видами деятельности и их передаче работодателям.

4. Передача функций по разработке исполняемых операций от работников к работодателям. Эта стадия закабаления труда совпадает с такой переменой в производстве, выделяемой историей экономического быта, как введение на производстве научной организации труда (HOT), происходившей в начале XX в. Как отмечал один из представителей движения за НOT американец Г.Л.Гантт, на современных великолепно оборудованных заводах [3, с. 3] рабочие предпочитают продавать свое рабочее время, а сколько надо сделать в рабочее время любят определять сами [3, с. 9], при этом рабочие не знают, каким способом лучше и быстрее выполнить данную операцию, и никто не занимается исследованием различных методов их исполнения и выбором лучших [3, с. 15], тогда как выяснив нормальный дневной урок для рабочего, выяснив вознаграждение, способное побудить рабочего исполнять этот урок, создав распорядок, при котором рабочие могли бы работать непрерывно с соответствующей продуктивностью [3, с. 8], можно было бы поднять производительность по сравнению с фактической 3 к 1 и гораздо больше [3, с. 6]. Другой представитель движения за внедрение НОТ, Г.Эмерсон, понятно, в рекламных целях, так как внедрение научной организации труда давно превратилось в бизнес, приводит вообще фантастический пример потери производительности благодаря тому, что методы исполнения операций определяют сами рабочие, в связи с чем приведем полную цитату из его труда «Двенадцать принципов производительности» (1912), где этот пример приводится: 
«Я вижу рабочего, строгающего кусочек стали величиною с визитную карточку. Я понятия не имею о том, для чего нужна эта работа, но, поглядев на нее с полминуты, сразу замечаю, что резец захватывает материал на протяжении дюйма, а шаг делается в три дюйма. Отсюда следует, что производительность каждого хода резца равна, если мы учтем задержку на обоих концах, всего 30\%. Я спрашиваю рабочего, какая у него сталь. Он отвечает: «Для синей стружки»; но очевидно, значение этих слов ему непонятно, так как стружка у него получается не синяя, а темно-серая (Г.Эмерсон имеет в виду, что по цвету стружки, т.е. по поведению отходов в ходе обработки заготовки, можно судить о скорости обработки.- примеч. авт.). Скорость работы станка втрое меньше, чем могла бы быть. Следовательно, эффективность скорости равна 33\%. / Заточка у резца остроконечная, а подача - 1/64 дюйма, тогда как следовало бы взять резец с круглым концом, а подачу установить в 1/16 дюйма. Стало-быть эффективность подачи равна 25\%. Глубина резания - минимальная, какую только допускают станок и резец, так что резец этот делает сначала три черновых прохода, а затем один чистовой, когда было бы вполне достаточно одного чернового и одного чистового. По глубине резания эффективность не превышает 50\%. Таким образом, общая производительность времени, затрачиваемого на эту работу, составляет $30 * 33 * 25 * 50=1,25 \%$, т.е. немногим более одного процента» [11, с. 132]. После передачи работником функций по разработке способа производства своей операции работодателю, когда работник получает инструкцию по ее исполнению от работодателя, закабаление труда работника завершается, и объективная (т.е. очищенная от влияния конъюнктурных факторов) оплата его труда достигает трансфертного, т.е. самого низкого, уровня.

Следует отметить, что в классической марксистской концепции закабаления труда, представленной, например, в «Истории труда» А.И. Тюменева, вышедшей в 1923 г., такая стадия закабаления труда, как внедрение на производстве НОТ, не выделяется, несмотря на то, что движение за внедрение на производстве НОТ приобрело широкую известность уже в самом конце XIX - начале XX в., в частности в нашей стране, где задолго до Октябрьской революции 1917 года его идеи широко пропагандировал, например, инженер Л.А.Левенстерн, имевший собственное издательство для соответствующих целей.

При этом в марксисткой концепции закабаления труда обязательно выделяется такая стадия его закабаления, предшествующая во времени внедрению на производстве НОТ, как введение машин. Марксистские авторы справедливо отмечают, что в результате внедрения машин прежние приемы труда, основанные на навыке и сноровке, стали все больше сводиться к наблюдению за действиями машины, к удалению от нее готовых изделий и доставлению ей материалов через определенные промежутки времени, что превратило работника (из автомата) в простой придаток машины [9, с. 99]. Однако, согласно теории альтернативных финансов, введение на производстве машин не знаменует очередной стадии закабаления труда, так оно не связано с очередным сокращением функций управления видом деятельности, находящихся в ведении работников. Главное, что после введения машин, как и до их введения, работник продолжил самостоятельно определять способ исполнения им его операции, хотя и осуществляемой теперь с помощью машины. Другое дело, что внедрение машин привело к очередному относительному сокращению спроса на труд и снижению оплаты труда рабочих по этой причине. Как писал В.И.Ленин, машины требуют меньше физического труда, и капиталисты ставят к ним женщин и детей, платя им меньшую оплату труда, вводя машины, капиталисты массами выталкивают рабочих с фабрик, создавая безработицу с тем, чтобы еще больше ухудшить положение рабочих - увеличить их рабочий день, отняв ночной отдых, превращение рабочего в придаток машины обесценивает его искусство, в связи с чем он может быть заменен простым чернорабочим, готовым работать за меньшую оплату труда, получая расчет при попытке отстоять себя [7, с. 90-91].

Согласно концепции инволюции, освобождение труда (от внешнего управления) должно начаться с возврата работникам функций по разработке осуществляемых ими операций, затем от управления отдельными операциями работники должны будут перейти к управлению всем производственным процессом, далее им будет возвращено право самостоятельно распределять свой труд во времени и, наконец, им будут возвращены функции по управлению сбытом и реализацией изготавливаемых ими продуктов. 
Логическим доказательством такого порядка освобождения труда является аналогичный процесс профессионального роста рабочего, решившего стать индивидуальным предпринимателем в данной отрасли или дослужиться до должности директора предприятия, представляющий собой индивидуальное освобождение труда, или освобождение собственного (а не общественного) труда. Разумеется, в связи с наличием в экономике обилия «нарушающих» причин, в реальности процесс освобождения труда может идти параллельно или начинаться с ранних стадий, в связи с чем концепция стадий указывает лишь на соответствующую тенденцию или на очередность преобладающего отмирания неэффективной управленческой практики. Статистическим обеспечением наблюдения за освобождением труда (которого на данный момент нет) могли бы быть систематические данные о долях труда современных работников или просто работников, исполняющих соответствующие управленческие функции, которые, при прочих равных условиях, должны последовательно снижаться или показывать тенденцию к формированию соответствующего соотношения между ними.

Следует отметить, что окончательное освобождение индивидуального труда на стационарных производствах, требующих использования соединенного труда нескольких рабочих, будет выглядеть как работа рабочих по договорам ГПХ.

Определенным подтверждением адекватности концепции стадий освобождения являются данные о снижении эффективности производственного труда при лишении его очередной порции функций по управлению видом деятельности или о росте его эффективности при возврате работникам соответствующих функций, или свидетельствующие об этом данные об изменении производительности труда на предприятиях или о вытеснении одних форм организации производства другими.

Неэффективность труда, прежде всего машинного, инструкции по исполнению которого готовятся инженерами без участия самих рабочих, была установлена, в частности, в СССР еще в середине 1930-х гг., а возврат к самостоятельной разработке работниками исполняемых ими операций, теперь уже только с помощью инженеров, стал осуществляться в ходе «стахановского движения», названного в честь донбасского шахтера Алексея Стаханова, который в 1935 г. в 14 раз перевыполнил норму по добыче угля. Как отмечают эксперты, с развитием стахановского движения неразрывно связан бурный рост потока рационализаторских предложений, изобретений и открытий, сделанных рабочими. Во второй пятилетке (1933-1937 гг.), благодаря стахановскому движению, производительность труда выросла на 82\% по сравнению с 63\% по плану. В третьей пятилетке произошел переход от индивидуальной стахановской работы к такой форме развития рассматриваемого процесса, как деятельность комплексных инженерностахановских бригад. Первая из них (бригада Гудова) возникла весной 1938 г. на станкостроительном заводе им. Орджоникидзе в Москве и прославилась тем, что усовершенствовала технологию ряда производственных участков цеха № 3 данного завода. Благодаря деятельности таких бригад произошло, в частности, широкое внедрение многоцикличной системы работы в горной промышленности (угольной, рудной и др.), на строительстве московского метрополитена, скоростных методов шахтного, промышленного и жилищного строительства. Так, в результате применения последних, в марте 1939 г. силами 14 тыс. узбекских колхозников был построен всего за 17 дней (вместо 2 лет по старым нормам) Ляганский канал, в августе 1939 г. 160 тыс. узбекских колхозников приступили к строительству Большого Ферганского канала им. И.В. Сталина длиной 270 км., осуществив его за 45 дней (вместо 6-7 лет). Только на заводах Наркомата тяжелой промышленности в IV квартале 1939 г. число стахановских бригад составило 2,5 тыс., тогда как в III квартале их было всего лишь 1176 [10].

Неэффективность труда, прежде всего машинного, сводимого к постоянному исполнению одних и тех же операций, также была установлена в ходе стахановского движения, а возврат к исполнению работниками ряда последовательных операций произошел в виде развития такой формы стахановского движения, как движение за совмещение профессий и специальностей, которое там, где последовательные операции исполнялись на станках, приняло форму совмещения станочных специальностей, став разновидностью движения многостаночников, опрокинувшего традиционное представление о том, что рабочий может эффективно работать лишь на одном станке. Многие стахановцы овладевали несколькими смежными станочными специальностями (фрезеровщик, токарь, шлифовщик 
и т.д.), число которых доходило до 5. В угольной промышленности был внедрен метод строенной работы, предложенный забойщиком П.Сытенко, когда на удлиненном в несколько раз уступе угольного пласта вместо 5 забойщиков с 5 отбойными молотками стали работать 3 забойщика с 2 молотками, но попеременно занимавшихся еще и креплением забоя. Важно отметить, что движение многостаночников привело к углублению технической революции, вызванной развитием стахановского движения, так как оно создало предпосылки для перехода к автоматической системе машин за счет изобретения приспособлений по установке и закреплению заготовок на станках и по съему со станков готовых деталей и их передаче на следующий станок. Так, на Сталинградском тракторном заводе была создана автоматизированная линия для изготовления ступицы и бандажа ведущего колеса трактора, состоящая из нескольких станков [10].

Важно отметить, что эволюция стахановского движения от разработки рабочими отдельных операций к совершенствованию их последовательностей (многостаночничество при машинном труде) подтверждает, что профессиональный рост рабочего начинается с полного освоения и усовершенствования ими собственной операции и продолжается в виде попыток усовершенствовать смежные операции. А это подтверждает концепцию стадий освобождения труда в части первой и второй стадий его освобождения.

Неэффективность в определенных случаях производительного труда, осуществляемого в помещениях работодателя и под его непосредственным контролем в течение установленного им рабочего дня, по сравнению с надомным трудом, была установлена, по крайней мере, еще в период развития фабричного производства, причем также в нашей стране, что привело даже к вытеснению фабричного производства надомным. Как сообщает М.И. Туган-Барановский в своем знаменитом произведении «Русская фабрика в прошлом и настоящем» (1900), в конце XVIII в. в России иностранцами были построены крупные бумаготкацкие фабрики, т.е. ткачество первоначально производилось работниками на самих фабриках. Однако уже с конца XVIII в. бумажные фабриканты стали раздавать пряжу крестьянам по домам, например во Владимирской области раздача пряжи по домам распространилась в 20-е гг. XIX в. [8, с. 214-215].
Неэффективность подчинения кустаря скупщику была установлена в XIX в. в той же хлопчатобумажной промышленности России, что привело к окончательному вытеснению в ней фабричного производства кустарным промыслом. Крестьяне, получая от бумажного фабриканта работу на дом, освоили соответствующее производство, затем стали покупать пряжу за свои деньги и продавать товар от своего имени на базарах [8, с. 215]. Как заключает М.И. ТуганБарановский, «...странным образом, развитие идет в совершенно обратном направлении, сравнительно с предполагаемым обычно: развитие идет не от «самостоятельного» кустаря, через наемную домашнюю промышленность, к фабрике, а, наоборот, от фабрики, через наемную домашнюю промышленность, к самостоятельному кустарю» [8, с. 216]. При этом соответствующая эволюция хлопчатобумажной промышленности говорит о том, что профессиональный рост рабочего продолжается в виде перехода его к труду по своему собственному трудовому распорядку и после этого заканчивается в виде превращения его в индивидуального предпринимателя. А это является подтверждением инволюционной концепции стадий освобождения труда в части двух последних стадий.

Следует отметить, что инволюционная концепция стадий освобождения труда ни в коем случае не является застывшей конструкцией с точки зрения этапов соответствующего освобождения (как и закабаления). Так, анализ концепций современного менеджмента, представленных, например, в книге западного ученого Р. Дафта «Менеджмент» (2006), позволяет выделить такую предпоследнюю стадию освобождения труда, как почти предприниматель. Р.Дафт приводит результаты внедрения в клининговой компании SOL Cleaning Services теории Y Д. Макгрегора, одним из которых стало фактическое превращение уборщиков и уборщиц в предпринимателей [4, с. 85], произошедшее, естественно, в результате делегирования им соответствующего объема функций по управлению клининговой деятельностью. Р.Дафт также приводит результаты внедрения на фирме Cementos Mexicanos (Cemex) концепции обучающейся организации, одним из которых стало фактическое превращение каждого цементовоза фирмы в самостоятельную бизнес-единицу, возглавляемую человеком, мыслящим как бизнесмен $[4$, с. 98].

Концепция стадий освобождения труда 
сформирована применительно к производственному труду. Очевидно, что она может быть применена и к труду по управлению, поскольку стадии профессионального роста, например, рядового бухгалтера, не отличаются от таковых производственного работника.

Выше уже отмечалось, что окончательное освобождение индивидуального труда на производствах, требующих соединенного труда нескольких рабочих, будет выглядеть как работа отдельных рабочих по договорам ГПХ. Как показано в статьях Ю.И.Будович, опубликованных в данном номере журнала «Экономические науки», российское государство препятствует оформлению трудовых отношений договорами ГПХ, стремясь обеспечить работников вытекающими из трудовых договоров социальными га- рантиями за счет предприятий, чем сдерживает рост эффективности труда и его повышение его мобильности и, следовательно, тормозит экономический рост в стране. Отсюда следует, что в настоящее время существенной преградой на пути освобождения труда в России выступает само российское государство. С точки зрения теории альтернативных финансов, политикой государства на рынке труда должна быть политика, целью которой является всемерное развитие труда по договорам ГПХ, в том числе стационарного производственного труда, а не удушение труда оковами трудового договора из благородного желания обеспечить трудящееся население страны постоянной копейкой и дешевыми социальными гарантиями за счет предприятий.

\section{Библиографический список}

1. Будович Ю.И., Будович М. С. Государственно-капиталистический и кооперативный пути перехода к коммунизму и партийная программа // Экономические науки. 2020. № 12 (193). C. 479-487. DOI: 10.14451/1.193.479.

2. Будович Ю.И., Лебедев К. Н. Место финансов в современной экономике (Экономика без финансов) / под ред. К. Н. Лебедева.- Краснодар: Издательство НИИ экономики ЮФО, 2020. 186 с.

3. Гантт Г.Л. Современные системы заработной платы и подбор рабочих в связи с доходностью предприятий.- СПб.: Изд. инж. Л. А. Левенстерна, 1913. 154 с.

4. Дафт Р. Менеджмент / Пер. с англ.-СПб.: Питер, 2006. 864 с.

5. Зибер Н. И. Очерки первобытной экономической культуры.-СПб.: Акционерное общество печатного дела «Издатель», 1899. 574 с.

6. История Всесоюзной Коммунистической партии большевиков. Краткий курс / ЛИТМИР. Электронная библиотека. URL: https://www.litmir.me/br/?b=14721\&p=3 (дата обращения: 30.12.2020).

7. Ленин В.И. Полное собрание сочинений. Издание пятое. Том 2. Издательство политической литературы, 1967. 677 (XIII) с.

8. Туган-Барановский М. И. Русская фабрика в прошлом и настоящем. Историко-экономическое исследование. Том І.Историческое развитие русской фабрики в XIX в.- СПб.: Издательство и книжный магазин О.Н.Поповой. $562(\mathrm{~V})$ с.

9. Тюменев А.И. История труда. Краткое руководство политической экономии.- Петроград: Рабочее кооперативное изд-во «Прибой», 1923. 208 с.

10. Хайкин Н. М. Трудовая слава: как развивалось движение передовиков-стахановцев / Рамблер / финансы. 16.10.2021. URL: https://finance.rambler.ru/economics/47397611-trudovaya-slava-kak-razvivalos-dvizhenieperedovikov-stahanovtsev/ (дата обращения: 25.10.2021).

11. Эмерсон Г. Двенадцать принципов производительности / Пер. с англ.- Ленинград: Техника управления, 1931.216 (XXII) c.

12. Юсупов Р.А. Революционная деятельность Ленина В.И. / Проза.py. URL: https://proza.ru/2020/08/29/234 (дата обращения: 28.12.2020). 